\title{
Slide haemagglutination test in hydatid disease: a correlative study of diagnostic procedures
}

\author{
R. M. MATOSSIAN, A. J. MAMO, AND R. DAKROUB \\ From the Department of Bacteriology and Virology, American University of Beirut, Beirut, Lebanon
}

SYNOPSIS Human 0 erythrocytes, treated with $1 \%$ formalin and subsequently exposed simultaneously to hydatid protein antigen and $0.1 \%$ chromic chloride, acquire the property of agglutinating on a slide when brought in contact with specific antiserum. This constitutes the basis of the slide haemagglutination test, an easy, quick, sensitive, and specific procedure, useful in the diagnosis of hydatid disease.

In previous communications (Mamo and Dakroub, 1974; Mamo et al, 1975) we described a diagnostic method based on the principle of binding hydatid antigen to human erythrocytes with the use of chromic chloride. When mixed on a slide with specific antiserum the sensitized cells produced a visible haemagglutination. Comparison of the slide haemagglutination (SHA) test with the tube method of Garabedian et al (1957) showed that the two procedures are equally sensitive and specific. We present the results of a correlative study of the SHA, tube haemagglutination (THA), complement-fixation (CF), and indirect fluorescent (IFA) tests in the diagnosis of patients with hydatidosis.

\section{Materials and Methods}

\section{BLOOD SAMPLES}

Serum samples were obtained from:

1. 57 patients with hydatid disease; of these, $32 \mathrm{had}$ hepatic and 25 pulmonary cysts;

2. 24 postoperative patients with no demonstrable cysts one year after surgery;

3. 100 controls; of these 50 were healthy adults and the rest were patients admitted to the hospital for miscellaneous conditions other than hydatid disease.

All samples were stored at $-20^{\circ} \mathrm{C}$.

\section{PROCEDURES}

\section{Slide Haemagglutination (SHA) Test}

This followed the method of Gold and Fudenberg (1967) with a number of modifications. Fresh human $0 \mathrm{Rh}$ positive or negative blood, in Alsever's solution, was washed three times in $0.9 \%$ saline, and the erythrocytes were packed by centrifugation.

Received for publication 15 July 1975.
Five drops of the packed cells were next suspended in $10 \mathrm{ml}$ of $1 \%$ formalin in saline and left at room temperature for 10 minutes. The erythrocytes were washed twice with saline and re-packed. Five drops of saline were added to the cells to make up a $50 \%$ suspension. This was added to $2.5 \mathrm{ml}$ of potent hydatid fluid antigen in a flask and, immediately after, $1 \mathrm{ml}$ of $0.1 \%$ freshly prepared chromic chloride solution in saline $\left(\mathrm{CrCl}_{3}, 6 \mathrm{H}_{2} \mathrm{O}-\mathrm{MW}\right.$ 266.45-BDH) was added. The mixture was gently shaken for exactly 4 minutes, after which the erythrocytes were washed twice in saline and packed. Fifteen drops of saline were added to the cells to constitute a $25 \%$ suspension. The sensitized cells retained their potency for about a week. Variations in the potency of the sensitized cells were at times observed with erythrocytes obtained from different donors. This necessitated testing multiple samples of blood.

Serum dilutions of 1:10,1:100, and 1:500 in saline were prepared in tubes. One drop of each dilution was added to a properly labelled area on a slide. One drop of the sensitized cell suspension was added to each dilution of the test sera and mixed with a wooden applicator. One drop of serum at 1:10, mixed with normal erythrocytes, was included as a control. The slides were put on a rotator and the results were read in 4 minutes. Visible clumps of erythrocytes were graded as varying from \pm to ++++ , depending on the degree of haemagglutination. The test was considered as positive if +++ or ++++ readings were observed at dilutions of $1: 100$ or above. Usually, a ++++ dilution at $1: 10$ was similarly positive at $1: 100$. Variations between \pm and ++ at 1:10 dilutions were considered as negative. Positive controls, of known titres, were included in each determination. 
Tube Haemagglutination (THA) Test

The tube method used by Garabedian (1971) was adopted after some modifications. The test was considered as positive if the serum titres were $1: 1280$ or above, doubtful at a range of $1: 80$ to $1: 640$, and negative at lower titres (Matossian and Araj, 1975).

\section{Complement-Fixation (CF) Test}

The microtitre technique described by Garabedian (1971) was adopted. The test was considered as positive at titres of $1: 8$ and above and doubtful at 1:4 (Matossian and Araj).

\section{Indirect Fluorescent Antibody (IFA) Test}

This followed the method of Matossian et al (1972). Freeze-dried antigens and human monospecific anti-IgG conjugates, obtained from the Wellcome Reagents Ltd, England, were used. The test was considered positive when immunofluorescence was observed at dilutions of 1:100 or above.

\section{Results}

Table I presents the results obtained by the SHA, THA, CF, and IFA tests in 57 patients with hydatid disease, 24 postoperative patients with no demonstrable cysts, 50 healthy Lebanese adults, and 50 patients with illnesses other than hydatid disease.

\begin{tabular}{|c|c|c|c|c|c|}
\hline & $\begin{array}{l}\text { No. of } \\
\text { Patients }\end{array}$ & $S H A$ & $T H A$ & $C F$ & $I F A$ \\
\hline Liver & 32 & & & & \\
\hline Positive & & 87 & 90 & 85 & 90 \\
\hline Doubtful & & - & 7 & 6 & - \\
\hline Negative & & 13 & 3 & 9 & 10 \\
\hline Lung & 25 & & & & \\
\hline Positive & & 72 & 76 & 68 & 72 \\
\hline Doubtful & & - & 16 & 8 & 0 \\
\hline Negative & & 28 & 8 & 24 & 28 \\
\hline $\begin{array}{l}\text { Postop. no } \\
\text { cysts }\end{array}$ & 24 & & & & \\
\hline Positive & & 17 & 8 & 8 & 33 \\
\hline Doubtful & & - & 63 & 29 & - \\
\hline Negative & & 83 & 29 & 63 & 67 \\
\hline Controls & 100 & & & & \\
\hline Positive & & 0 & 0 & $4^{1}$ & $12^{2}$ \\
\hline Doubtful & & - & 0 & 8 & - \\
\hline Negative & & 100 & 100 & 88 & 88 \\
\hline
\end{tabular}

Table Percentages of positive, doubtful, and negative reactions in SHA,THA,CF, and IFA tests in hydatid patients with hepatic or pulmonary cysts, others with no demonstrable cysts undergoing postoperative follow-up, and non-hydatid controls

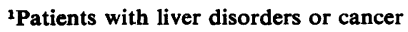

In hydatid patients the percentage of positive reactors by the SHA was not significantly different from that observed by the three other methods. The doubtful results observed in the $\mathrm{HA}$ and CF tests, although suggestive of disease in patients with additional symptoms, were difficult to interpret in postoperative patients without demonstrable cysts. In this last group, the highest percentage $(83 \%)$ of negative reactors was observed by the SHA test. This may be an advantage if further follow-up studies demonstrate that such readings are not misleading. The specificity of the SHA and THA tests appears to be similar. The positive reactors in the controls, observed by the CF and IFA tests, had chronic liver disease or cancer.

These results suggest that the SHA test may serve as a possible alternative method to any one of these tests if additional studies prove its definitive diagnostic value.

\section{Discussion}

The sensitivity and specificity of the serological tests employed in the diagnosis of hydatid disease have been studied by many laboratories (Kagan, 1968; Matossian et al, 1972; Matossian and Araj, 1975). oे As a diagnostic procedure the haemagglutination test is considered the most satisfactory in primary infection. The combined use of the haemagglutination and $\mathrm{CF}$ tests has led to the detection of recurrent illness (Matossian and Araj, 1975). A substitute method, to be acceptable, must satisfy a need created by the shortcomings of presently available procedures. Besides its sensitivity and specificity, a test must also be measured by the ease of its performance. The CF and IFA tests require elaborate methods and their use has been confined to qualified laboratories. The THA test requires a number of steps which are time-consuming. It also remains positive at moderate titres long after surgery. These minor hindrances do not necessarily detract from the usefulness of the test. The SHA test is 을 easier and simpler to perform. It has been shown to be as sensitive and specific as the THA in the diagnosis of hydatid disease. Furthermore, it does $\bar{N}$ not require serum inactivation and erythrocyte $\sigma$ tanning at $37^{\circ} \mathrm{C}$. It can be run with fresh human $0 \stackrel{\sim}{ }$ erythrocytes. Readings are taken in 4 minutes. In a N limited number of patients the test was positive with plasma samples. Hence blood samples can be obtained in heparinized capillary tubes and may be $\frac{C}{\Phi}$ used for epidemiological surveys. Similarly, blood $\stackrel{\mathscr{\rho}}{\rightarrow}$ obtained on filter paper may be used if enough 7 samples are made available to test the usefulness of 0 the method. The few samples we tested were reactive $\stackrel{\square}{\overparen{D}}$ to the SHA. The bentonite flocculation and latex $\underset{\mathbb{Q}}{\mathbb{Q}}$ agglutination have been used as slide agglutination $\bar{\sigma}$ tests. However, the variations observed in their sensitivity and specificity have often made their 
interpretation difficult (Kagan et al, 1966; Kagan, 1968).

The use of chromic chloride by Gold and Fudenberg (1967) and Gold (1968) to bind protein antigens to erythrocytes has opened an additional approach to diagnostic immunology. Thus erythrocytes, selectively sensitized by protein antigens, may prove to be useful in the rapid diagnosis of various parasitic diseases. As applied to hydatid disease, the SHA test may prove valuable in diagnostic, epidemiological, and veterinary fields of study.

\section{References}

Garabedian, G. A. (1971). Evaluation of the reactivity of hydatid whole-scolex antigen in hydatid disease serology. Ann. trop. Med. Parasitol., 65, 385-391.

Garabedian, G. A., Matossian, R. M., and Djanian, A. Y. (1957). An indirect hemagglutination test for hydatid disease. J. Immunol., 78, 269-272.

Gold, E. R. (1968). Agglutination of red cells by $\mathrm{CrCl}_{3}$ solutions: differential agglutinability of coated and uncoated cells from various donors. Vox Sang. (Basel), 14, 147-150.

Gold, E. R. and Fudenberg, H. H. (1967). Chromic chloride: a coupling reagent for passive hemagglutination reactions. J. Immunol., 99, 859-866.

Kagan, I. G. (1968). A review of serological tests for the diagnosis of hydatid disease. Bull. Wld Hlth Org., 39, 25-37.

Kagan, I. G., Osimani, J. J., Varela, J. C., and Allain, D. S. (1966). Evaluation of intradermal and serologic tests for the diagnosis of hydatid disease. Amer. J. trop. Med. Hyg., 15, $172-179$.

Mamo, A. J. and Dakroub, R. (1974). Un test rapide d'hémagglutination indirecte dans le diagnostic de la maladie hydatique. J. med. liban., 27, 223-228.

Mamo, A. J., Matossian, R. M., and Dakroub, R. (1975). Etude comparative de deux méthodes d'hémagglutination indirecte dans le sérodiagnostique de la maladie hydatique. Arch. Mal. Tube Dig. de Paris (In press).

Matossian, R. M. and Araj, G. F. (1975). Serologic evidence of the postoperative persistence of hydatid cysts in man. J. Hog. (Lond.) (In press).

Matossian, R. M., Kane, G. J., Chantler, S. M., Batty, I. and Sarhadian, H. (1972). The specific immunoglobulin in hydatid disease. Immunology, 22, 423-430. 
available. Both authors have an established reputation in this field.

The book begins with a brief historical review which is followed by chapters on the techniques of nerve biopsy and histological processing, and on normal structure. A useful inclusion is a section on preparative artefact. Recent years have witnessed the growth of a large literature, often in journals that should have been better informed, based entirely on artefactual appearances in electron microscope preparations. The next two chapters are devoted to a consideration of the basic pathological mechanisms, including axonal degeneration and regeneration and segmental demyelination and remyelination, and the appearances in individual disorders. The latter is comprehensive but not exhaustive. Occasional misinterpretations from the literature, such as the report on the occurrence of infarcts in peripheral nerve in diabetic neuropathy, have crept in. The topic of peripheral nerve tumours has been given more detailed consideration. This is a difficult field, and the chapter on this topic constitutes a particularly valuable part of the book. The final appendix comprises a short practical guide to the examination of nerve biopsies.

Outside specialised units, peripheral nerve pathology has often been poorly executed in the past, so much so that a report prepared by the World Federation of Neurology in 1970 recommended that nerve biopsy should be undertaken only by units possessing special expertise. This book should contribute towards rectifying this situation.

P. K. THOMAS

Fundamentals of Clinical Chemistry. Edited by Norbet W. Tietz. (Pp. xxvi + 1263; illustrated; $£ 24.00$.) Philadelphia, London, Toronto: W. B. Saunders. 1976.

The second edition of this book is most welcome for during the past six years, since the first edition, many techniques which were largely of a research nature have now been adopted in the diagnostic chemical laboratory. The book is written for students of medicine, biochemistry, and medical technology with an emphasis on the fundamentals of clinical chemistry. There is not only information on analytical procedures and their chemical principles, but also discussion of the clinical significance of the results. Much new information is included on immunochemical techniques, including radioimmunoassay, and methods for the estimation of serum pro- teins and lipoproteins. There is up-to-date information on quality control procedures, laboratory instrumentation, and the use of computers in clinical chemistry.

The book is comprehensive in its scope, but future editions will be improved by a separate chapter on paediatric and antenatal clinical chemistry. Many techniques relevant to fetoplacental function, antenatal diagnosis of inherited metabolic disease, and congenital malformations are described but scattered throughout the text. There is some inconsistency in the use of units. It would have been better to use either traditional or SI units consistently, and to provide readers with conversion tables as well as factors.

The contributors are largely from North America but now also include Donald Moss (enzymes) and Gregor Grant (proteins and amino-acids) from the United Kingdom and Siggaard-Anderson (blood gases) from Denmark, giving the second edition a more international approach.

The price is competitive when compared with that of similar books but is still expensive. Nevertheless, this is a valuable book to purchase both for the laboratory and for the library.

BRENDA M. SLAVIN

Guide to the Collection and Transport of Virological Specimens (including Chlamydial and Rickettsial Specimens). By C. R. Madeley. (Pp. 40; illustrated; Sw. fr. 10.) Geneva: World Health Organization. 1977.

There can be nothing more wasteful of time and effort than to examine specimens which have been taken at the wrong time, from the wrong site, and transported in the wrong way. There are undoubtedly situations where the services of a specialised virus laboratory are required, but the clinician or epidemiologist must take the specimen from the appropriate site, place it in the correct medium, and package it in a way which ensures not only preservation but the safety of those concerned in its handling. Extra special precautions are required for sending samples from one country to another. It is with these points in mind that this book has been written, and Dr C. R. Madeley covers all these points and more in a clear and lucid fashion. It should be at hand in all virus laboratories, not only to refresh the minds of laboratory workers but also to provide a readily available means of educating those who are taking and transporting specimens to the laboratory. It is to be hoped that the book will find its way into their hands as well.

D. TAYLOR-ROBINSON

Serology of Fungal Infection and Farmer's . Lung Disease. A Laboratory Manual. Edited by E. G. V. Evans. (Pp. 36; illustrated; $£ 1.50$.) Obtainable from Dr F. W. Chattaway, Department of Biochemistry, The University of Leeds, 9 Hyde Terrace, Leeds LS2 9LS.

This laboratory manual sets out the serological tests that are available to assist in the diagnosis of candidiasis, aspergillosis, cryptococcosis, histoplasmosis, coccidioidomycosis, blastomycosis, and farmer's lung. The methods for the tests and for the preparation of the appropriate antigens and antisera are concisely explained. An interpretation of results is made at the end of each section. Details of apparatus, formulae, and of the commercial availability of serodiagnostic kits are given in an appendix. This book succeeds in its purpose of providing details of the simpler serological tests in current use, and workers interested in this field should find much of practical value in it.

YVONNE M. CLAYTON

\section{Correction}

Slide haemagglutination test in hydatid disease: a corrective study of diagnostic procedures. Journal of Clinical Pathology, 29, 39 (1976).

The authors' addresses are as follows:

R. M. Matossian, Department of Bacteriology and Virology, American University of Beirut.

A. J. Mamo, French Faculty of Medicine and Pharmacy of Beirut; Department of Microbiology, Hôtel-Dieu de France Hospital, Beirut.

R. Dakroub, Lebanese Ministry of Education. 